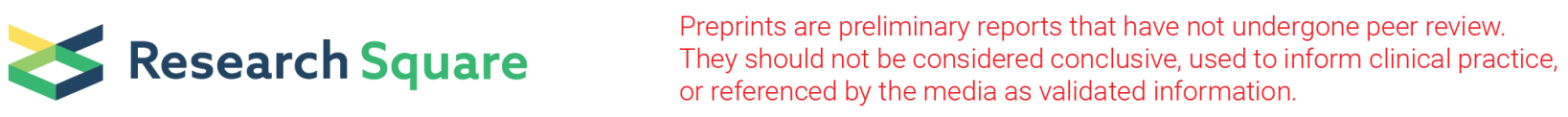

\title{
Ambulatory Care-Sensitive Hospital Admissions: Access to Care or Population Health?
}

Joe Feinglass ( $\square$ j-feinglass@northwestern.edu )

Northwestern University Feinberg School of Medicine https://orcid.org/0000-0002-3665-8897

Ana Reyes

Northwestern University Feinberg School of Medicine

Research article

Keywords: ambulatory care sensitive conditions, population health, poverty, primary care access, hospital use

Posted Date: December 21st, 2020

DOI: https://doi.org/10.21203/rs.3.rs-131593/v1

License: (c) (1) This work is licensed under a Creative Commons Attribution 4.0 International License. Read Full License 


\section{Abstract}

\section{Background}

Admission rates for ambulatory care-sensitive conditions (ACSCs) are often used by health systems as a measure of access to effective primary and preventive care. However, there is debate about whether ACSC admissions primarily reflect social determinants of population health and are largely insensitive to ambulatory care quality. To provide evidence for this debate, this study analyzes adult ACSC admissions of Cook County, Illinois residents to 173 Illinois hospitals from 2016-2018.

Study Design

Retrospective cohort study.

Methods

Hospitalized patients were categorized by sex, by race and ethnicity (Non-Hispanic White, Non-Hispanic Black, Hispanic, Asian, other/unknown), and by primary insurance status (private, Medicaid, Medicare, uninsured, other/unknown) and by whether the admission was on the weekend. Agency for Healthcare Research and Quality Prevention Quality Indicators were calculated to compute ACSC hospitalization rates per 1000 residents across four census data-defined zip code poverty level areas $(>20 \%, 10-19.99 \%$, $5-9.99 \%$ and $<5 \%$ poor households). ACSC hospitalization rates were compared to rates for all other medical and surgical conditions across areas. Patient age groups were categorized as $20-44,45-64$, and $>65$.

Results

There were 1,384,880 medical and surgical admissions of Cook County Residents age 20 and older from 2016-2018. There were 181,836 (13.3\%) admissions classified as ACSC admissions by the overall composite PQI 90 . Residents of the highest poverty level zip code area had ACSC rates up to $70 \%$ higher than the most affluent zip code area. However, all other medical admissions had a $102 \%$ higher rate in the poorest versus most affluent areas, with twice the admission rate for the most severely ill patients (Charlson Score $>3$ ). By comparison, surgical DRG admission rates had only a $6 \%$ difference across areas.

\section{Conclusions}

These findings indicate that ACSC admission rates mirror other medical, but not surgical, causes of admissions as well as illness severity generally. While socioeconomic differences in access to care undoubtedly exist, use of the ACSC admission rate as a measure of access to primary care may obscure the far more consequential social determinants of chronic illness and hospital use that primarily drive hospital admissions for low income populations. 


\section{Background}

Ambulatory care-sensitive conditions (ACSCs) have been defined as conditions for which hospital care was potentially preventable if a patient had received timely and effective primary care. The concept of ACSCs was first introduced by Billings in 1993 to examine the variation in emergency room admission rates between low-income and high-income areas of New York City.(1) That study found populationbased hospitalization rates for these 'primary care treatable' conditions were significantly higher in lowincome as compared to more affluent areas.

Given consensus opinion about the value of screening, early identification and aggressive primary care management of chronic disease, differential rates of ACSC hospitalization were assumed to reflect differences in barriers to effective outpatient care.(2) Area variation in the admission rate for ACSCs was assumed to be inversely proportional to level of access to high quality primary care, with ACSC hospitalizations significantly higher among lower income populations with poor access to primary and preventive care. A number of studies of insurance status, health literacy, and local availability of high quality chronic disease management have also documented the effects of timely primary care on hospital use.(3-6) Interventions to improve access to high quality primary care are therefore expected to lead to a decrease in ACSC hospital admission rates. $(7,8)$

The frequency of ACSC admissions has now become a well-established primary care quality measure based on International Classification of Disease (ICD) hospital discharge codes.(9) With support from the Institute of Medicine, the Agency for Healthcare Research and Quality (AHRQ) developed an ICD (now ICD10) ACSC coding algorithm for hospital discharge data and created the Prevention Quality Indicators (PQIs).(10) The PQIs can be used with hospital inpatient discharge data from 45 states who participate in the AHRQ Hospital Cost and Utilization database. ACSC hospital admission rates are thus a relatively simple quality metric for health system managers to monitor access to effective primary care for their patient populations.

This study addresses a debate about the validity of ACSC admissions as prevention quality indicators. An alternative view is that ACSC admission rates primarily reflect population health status, and in fact, may be largely insensitive to the availability of ambulatory care. Use of the ACSC admission rate as a measure of access to primary care may thus obscure the far more consequential social determinants of chronic illness and hospital use. We sought to determine the extent to which ACSC admission rates primarily reflect underlying social determinants of health driving all medical admissions, as opposed to ACSC admissions being a marker for differential access to high quality preventive and primary care.

To provide evidence about this debate, this study analyzes population-based ACSC admission rates of residents of Cook County, Illinois, which is home to almost 5.2 million residents in and around Chicago and has a diverse population encompassing a very wide socioeconomic spectrum. We hypothesized that area variation in medical DRG admissions and overall illness severity would reflect population health, while surgical admissions were much more likely to represent 'referral sensitive conditions' and would be higher in more affluent areas of the County.(11) 


\section{Methods}

\section{Data Sources and Study Sample}

We analyzed 2016-2018 hospital inpatient discharge data from 173 Illinois hospitals for adult patients living in Cook County zip codes, using the Illinois Hospital Association COMPdata hospital discharge database.(12) Childbirth related hospitalizations were excluded, as were hospitalizations for patients under age 20. Patient zip codes were matched to 2017 five-year American Community Survey (ACS) zip code tabulation areas (ZCTAs) census data. The proportion of ZCTA households living at or below poverty level was used to create four areas of the county reflecting < $5 \%$ poverty households, $5-9.99 \%$ poverty households, $10-19.99 \%$ poverty households and $20 \%$ or greater poverty households, respectively. ZCTA level poverty levels in Cook County were mapped using ESRI ArcGIS PRO software (Plantation, FL). Figure 1 displays a Cook County map showing these ZTCA poverty level areas.

Patient age groups were categorized as $20-44,45-64$, and $>65$. Patients were also categorized by sex, by race and ethnicity (Non-Hispanic White, Non-Hispanic Black, Hispanic, Asian, other/unknown), and by primary insurance status (private, Medicaid, Medicare, uninsured, other/unknown) and by whether the admission was on the weekend.

Publicly available AHRQ software was used with the principal and up to 24 secondary ICD10 diagnosis and procedure codes to identify 10 types of ACSC admissions. The PQIs include an aggregate acute (PQI 91), chronic (PQI 92) and overall (acute and chronic combined) composite (PQI 90). Other, non-ACSC admissions were categorized by DRGs, grouped into all other medical or all other surgical causes of admission. ICD10 coding was also used to compute the Charlson score of all admissions, a measure of the presence and severity of 20 chronic disease comorbidities.(13) We classified the most severely ill patients as those with a Charlson score of four or more.

\section{Statistical Analysis}

Patient characteristics of ACSC admissions were compared to characteristics for all other admissions of Cook County residents using chi square tests to determine the significance of differences between ACSC admission patients and other hospitalized patients. Admission rates per 1000 Cook County residents for each admission type were calculated with area admission frequencies as the numerator and the four strata of ZCTA area poverty level population estimates as the denominator. Separate rates were calculated for the three age groups and for all adults age 20 and over. Rates are presented as an average annual admission rate across the three years of study data. The significance of differences in rates across poverty-level areas was compared using Stata Version 15 (College Station, Texas) chi square tests for aggregate data. Hospital 18-month death rates were stratified as 1-19, 20-49 and $50+$ per 100,000. This study of publicly available, de-identified data is exempt from institutional review board approval.

\section{Results}


There were 1,384,880 medical and surgical admissions of Cook County Residents age 20 and older from 2016-2018. There were 181,836 (13.3\%) admissions classified as ACSC admissions by the overall composite PQI 90. Appendix I presents the frequencies of each ACSC admission by specific PQI categories; including 142, 260 admissions classified as chronic and 39,576 as acute conditions. The most frequent ACSC admissions were for heart failure $(n=63,005)$, COPD $(n=37,038)$ and composite diabetes $(n=31,678)$.

Table 1 presents the proportion of ACSC admissions by patient characteristics. While there were significantly different proportions for a number of characteristics in this 1.37 million admission sample, these differences in each category of ACSC admissions were generally less than $1 \%$ and ACSC patients were essentially similar to other hospitalized Cook County residents. Table 1 illustrates the importance of presenting admission rates per capita by the fact that only $14.6 \%$ of residents of Cook County were age 65 or older, but older residents accounted for $45.7 \%$ of all county resident admissions. Similarly, NonHispanic Black residents accounted for $23.9 \%$ of Cook County residents but $35.2 \%$ of all county resident hospital admissions.

\section{ACSC and Other Admission Rates per 1000 County Residents}

Figure 2 presents monthly, modestly declining ACSC admission rates over the 36 month study period for each of the four ZCTA poverty-level areas. The rates for the three areas with $<20 \%$ poverty are similar, with the lowest monthly rates for residents of the most affluent area. However, residents of the highest poverty level area had strikingly higher monthly ACSC admissions, with rates per 1000 up to $40 \%$ higher than the other areas.

Table 2 provides direct comparisons of ACSC average annual admission rates per 1000 by poverty-level area, including rates for each age group, to rates for other medical and surgical DRGs and admission rates for the highest Charlson Score patients. There is a very evident gradient with per capita ACSC admission rate increasing as the proportion of ZCTA residents living in poverty level households increases $(p<0.0001)$. Comparing admissions for all residents age 20 or older, residents of the lowest poverty area (20\% poor or more) had an approximately $70 \%$ higher ACSC admission rate than residents of the lowest (<5\% poor) poverty area.

An even higher poverty level gradient is apparent when looking at admission rates for all other medical DRGs. Here the poorest area had an approximately $102 \%$ higher admission rate than the most affluent area. However, differences across areas in admission rates for surgical DRGs, although statistically significant, were remarkably similar across areas, with only a $6 \%$ difference between residents of the poorest and most affluent areas. The largest surgical admission rate difference was for age 65 and older residents where residents of the highest poverty area had an $18 \%$ lower rate of undergoing surgical procedures. Finally, patients admitted with a Charlson Score of four or more reflected the same gradient as seen for ACSC and other medical DRGs. The rate of high severity admissions was approximately twice 
as great among residents of the highest poverty level area as among residents of the most affluent area. Figure 3 provides a graphical view of admission rates for each condition, showing the essentially similar pattern for ACSC, medical DRG and Charlson score admissions. By comparison, surgical DRG admission rates are relatively uniform across areas.

\section{Discussion}

In its PQI documentation, the AHRQ acknowledges that "complexity of the relationship between socioeconomic status, access to care, and PQI rates makes it difficult to delineate how much of the observed relationships are due to true access to care difficulties in potentially underserved populations, or due to other patient characteristics, unrelated to quality of care, that vary systematically by socioeconomic status. For some of the indicators, patient preferences and hospital capabilities for inpatient or outpatient care might explain variations in hospitalizations. In addition, environmental conditions that are not under the direct control of the health care system can substantially influence some of the PQIs. For example, the COPD and asthma admission rates are likely to be higher in areas with poorer air quality."(14) This AHRQ disclaimer raises the question of whether area variation in ACSC admission rates really just reflects social determinates of health, with variation in area hospitalization rates primarily driven by the effects of social status on health.(15)

\section{The Debate about the Meaning of ACSC Hospital Use}

ACSC admission rates are increasingly being used as an indicator of access to care and as a measure for evaluating health care delivery system innovations over time.( $(7,16,17)$ The concept that timely outpatient care can prevent hospital admissions for a variety of conditions has gained momentum with the advent of Medicare readmission penalties and the proliferation of accountable care financial incentives. In this environment, there is evidence that programs like hospital transitional care and home based primary care for seriously ill patients are associated with significant reductions in hospital use.(18, 19) In particular, studies of ACSC emergency department (ED) visits have raised important questions about the lack of timely, available primary care for chronic disease patients with worsening symptoms. Rates of ACSC emergency department outpatient visits have been used to evaluate the effects of insurance status and other barriers to effective outpatient care,(20) as well as their impact on ED overcrowding. $(21,22)$ This ED research would seem to make trends in ACSC hospital use a good outcome metric for evaluating efforts to improve the primary care delivery system and insure access to care so as to reduce unwarranted hospital use $(5,23,24)$

\section{Are Differences in Hospital Use Sensitive to Ambulatory Care Access or Population Health Status?}

However, our findings indicate that ACSC admission rates reflect the same socioeconomic gradient of population-based hospital use for largely non-elective, medical DRG admissions and admissions of the most severely ill patients. Our study thus mirrors recent studies from Ireland and England that found 
ACSC ED admissions were driven by essentially the same socioeconomic, insurance status and hospital factors as all other ED admissions,(25) and that there was no evidence of differences in primary care use prior to ACSC or other hospitalizations.(26) A Canadian study likewise concluded that ambulatory care visits were actually more common among lower income patients prior to ACSC hospitalizations.(27) There are undoubtedly important differences in access to care by socioeconomic status. This may be reflected in the relatively smaller (but still significant) difference in poverty level area medical admission rates for patients age 65 and over. Older patients are universally covered by Medicare, while many lower income patients age 20-64 remain uninsured or are covered by Medicare or low quality private insurance. The resulting access differences may in part be driving the steeper gradient in per capita admission rates across areas. However, If the ACSC admission rate is primarily tracking population health status, fundamentally driven by social determinants of health, its status as a metric for access to care is in doubt. Population health status for all adults as measured by hospital admission rates across the Cook County ZCTA poverty levels in this study are primarily driven by well-known lifecourse socialepidemiologic factors.(28) Because most of these social determinants of health remain outside the scope of health care delivery systems, the idea that ACSC admission rates are a measure of access to care may be mistaken, and many ACSC admissions may only be retrospectively 'preventable.'(29)

\section{Surgical DRG Admission Rates and Area Variation in Hospital Use}

One interesting finding, deserving of further study, was the relative lack of differences across Cook County zip code poverty areas in non-ACSC surgical admissions. While we did not further analyze area differences in surgery, this finding is likely related to the effect of 'referral sensitive' elective surgical admissions, which have higher use rates in more affluent areas, a phenomenon described in 1993 by Caper.(11) This finding about the intensity of surgical care underscores the problem of using billing and medical record coding of health system utilization as a proxy for population health. Recent studies have shown what is described as 'observational intensity bias', where regions with higher levels of discretionary care appear to have sicker populations due to increased rates of coded utilization, despite no apparent differences in these areas for population-level mortality rates or independent, survey based measures of population health.(30) This has led to calls for health risk adjustment to be based on population-based measures of area illness severity such as the percent of the population at or below poverty, rather than coded comorbidities. $(30,31)$

\section{Limitations}

The most significant limitation of this analysis is the inability to link individual patients across episodes of care so as to empirically assess patients' access to outpatient care prior to an ACSC hospitalization. Illinois hospital data do not have this capability, which may require more clinically detailed electronic medical record data. Also, we defined areas in Cook County using the proportion of a zip code level population living in poverty. However, this measure may not fully capture the extremes of wealth and poverty which overlay the very high level of residential racial segregation in the County. The proportion of 
the County's non-Hispanic Black population ranged from $8.1 \%$ in the lowest poverty area to $73.7 \%$ of the population in the highest poverty level area. Measures such as the Index of Concentration at the Extremes may provide a better method of classifying social deprivation.(32) Finally, we chose to study Cook County because we live here and are involved in public health policy here. While our population is representative of many large urban areas, our conclusions may not hold for exurban and rural regions.

\section{Conclusion}

Study findings support the primary role of population health as the primary driver of both ACSC and other medical admissions. This does not at all preclude the idea that improving primary care can reduce emergent hospital use, or that barriers to care increase the likelihood of most causes of hospitalization. However, use of the ACSC admission rate as a measure of access to primary care has yet to be validated at the individual patient level. The use of ACSCs as 'prevention' indicators may obscure the far more consequential role of social determinates of chronic illness and hospital use.

\section{Abbreviations}

ACSC Ambulatory Care Sensitive Condition

AHRQ Agency for Healthcare Research and Quality

COPD Chronic Obstructive Pulmonary Disease

DRG Diagnosis Related Group

ED Emergency Department

ICD International Classification of Diseases

PQI Prevention Quality Indicator

ZCTA Zipcode Census Tract Area

\section{Declarations}

This study of publicly available, deidentified data was ruled exempt by the Northwestern University IRB. The data analyzed-are available from the corresponding author on reasonable request. Neither author has any conflicts of interest or competing interests and both authors participated in the conceptualization, analysis and drafting of the manuscript and approved this submission. There is no funding source for this research.

- Ethics approval and consent to participate: This study of de-identified, publicly available data is IRB exempt 
- Consent for publication: NA

- Availability of data and materials: the datasets used and/or analyzed during the current study are available from the corresponding author on reasonable request.

- Competing interests: None

- Funding: None

- Authors' contributions: Both authors contributed to study design analysis, and writing

- Acknowledgements: None

\section{References}

1. Billings J, Zeitel L, Lukomnik J, et al. Impact of socioeconomic status on hospital use in New York City. Health Aff (Millwood). 1993;12(1):162-173.

2. Weissman JS, Gatsonis C, Epstein AM. Rates of avoidable hospitalization by insurance status in Massachusetts and Maryland. JAMA. 1992;268(17):2388-2394.

3. Bindman AB, Grumbach $K$, Osmond D, et al. Preventable hospitalizations and access to health care. JAMA. 1995;274(4):305-311.

4. Cheung PT, Wiler JL, Lowe RA, et al. National study of barriers to timely primary care and emergency department utilization among Medicaid beneficiaries. Ann Emerg Med. 2012;60(1):4-10 e12.

5. Oster A, Bindman AB. Emergency department visits for ambulatory care sensitive conditions: insights into preventable hospitalizations. Med Care. 2003;41(2):198-207.

6. Pezzin LE, Bogner HR, Kurichi JE, et al. Preventable hospitalizations, barriers to care, and disability. Medicine (Baltimore). 2018;97(19):e0691.

7. Saha S, Solotaroff R, Oster A, et al. Are preventable hospitalizations sensitive to changes in access to primary care? The case of the Oregon Health Plan. Med Care. 2007;45(8):712-719.

8. Ansari Z, Laditka JN, Laditka SB. Access to health care and hospitalization for ambulatory care sensitive conditions. Med Care Res Rev. 2006;63(6):719-741.

9. Laditka JN, Laditka SB, Mastanduno MP. Hospital utilization for ambulatory care sensitive conditions: health outcome disparities associated with race and ethnicity. Soc Sci Med. 2003;57(8):1429-1441.

10. Prevention Quality Indicators Overview. 2019; https://www.qualityindicators.ahrq.gov/modules/pqi_resources.aspx.

11. Elixhauser A J, J, Coopey, M. Guide to Prevention Quality Indicators. Agency for Healthcare Research and Quality;2001.

12. Jones NL, Gilman SE, Cheng TL, et al. Life Course Approaches to the Causes of Health Disparities. Am J Public Health. 2019;109(S1):S48-S55.

13. Caper P. The microanatomy of health care. Health Aff (Millwood). 1993;12(1):174-177.

14. COMPdata Informatics. 2019; https://www.compdatainfo.com/Home.aspx. 
15. Deyo RA, Cherkin DC, Ciol MA. Adapting a clinical comorbidity index for use with ICD-9-CM administrative databases. J Clin Epidemiol. 1992;45(6):613-619.

16. Basu J. Has Access to Care Changed in Minority Communities? A Study of Preventable Hospitalizations Over Time in Selected States. J Ambulatory Care Manage. 2014;37(4):314-330.

17. Carneiro CS. Hospitalisation of ambulatory care sensitive conditions and access to primary care in Portugal. Public Health. 2018;165:117-124.

18. Feinglass $\mathrm{J}$, Mallama CA, Rogers A, et al. Using hospital use trends to improve transitional care. Healthc (Amst). 2018;6(4):259-264.

19. Feinglass J, Norman G, Golden RL, et al. Integrating Social Services and Home-Based Primary Care for High-Risk Patients. Popul Health Manag. 2018;21(2):96-101.

20. Dresden SM, Feinglass JM, Kang R, et al. Ambulatory Care Sensitive Hospitalizations Through the Emergency Department by Payer: Comparing 2003 and 2009. J Emerg Med. 2016;50(1):135-142.

21. Hoot NR, Aronsky D. Systematic review of emergency department crowding: causes, effects, and solutions. Ann Emerg Med. 2008;52(2):126-136.

22. Smulowitz PB, Honigman L, Landon BE. A novel approach to identifying targets for cost reduction in the emergency department. Ann Emerg Med. 2013;61(3):293-300.

23. Rust G, Ye J, Baltrus $P$, et al. Practical barriers to timely primary care access: impact on adult use of emergency department services. Arch Intern Med. 2008;168(15):1705-1710.

24. Wen $\mathrm{H}$, Johnston KJ, Allen L, et al. Medicaid Expansion Associated With Reductions In Preventable Hospitalizations. Health Aff (Millwood). 2019;38(11):1845-1849.

25. Lynch B, Fitzgerald AP, Corcoran $P$, et al. Drivers of potentially avoidable emergency admissions in Ireland: an ecological analysis. BMJ Qual Saf. 2019;28(6):438-448.

26. Vuik SI, Fontana G, Mayer E, et al. Do hospitalisations for ambulatory care sensitive conditions reflect low access to primary care? An observational cohort study of primary care usage prior to hospitalisation. BMJ Open. 2017;7(8):e015704.

27. Roos LL, Walld R, Uhanova J, et al. Physician visits, hospitalizations, and socioeconomic status: ambulatory care sensitive conditions in a canadian setting. Health Serv Res. 2005;40(4):1167-1185.

28. Geronimus AT. Deep integration: letting the epigenome out of the bottle without losing sight of the structural origins of population health. Am J Public Health. 2013;103 Suppl 1:S56-63.

29. Feinglass J, Shively VP, Martin GJ, et al. How 'preventable' are lower extremity amputations? A qualitative study of patient perceptions of precipitating factors. Disabil Rehabil. 2012;34(25):21582165.

30. Wennberg DE, Sharp SM, Bevan G, et al. A population health approach to reducing observational intensity bias in health risk adjustment: cross sectional analysis of insurance claims. BMJ. 2014;348:g2392.

31. Wennberg JE. Forty years of unwarranted variation-and still counting. Health Policy. 2014;114(1):12. 
32. Krieger N, Kim R, Feldman J, et al. Using the Index of Concentration at the Extremes at multiple geographical levels to monitor health inequities in an era of growing spatial social polarization: Massachusetts, USA (2010-14). Int J Epidemiol. 2018.

\section{Tables}

\section{Table 1}

Ambulatory Care Sensitive Hospital Admissions for Residents of Cook County Illinois, 2016-2018, by Patient Characteristics 


\begin{tabular}{|c|c|c|c|c|}
\hline & $\begin{array}{l}\text { Sample } \\
\text { Percent All } \\
\text { Admissions }\end{array}$ & $\begin{array}{l}\text { Percent Acute } \\
\text { Composite (PQI } \\
\text { 91) Admissions }\end{array}$ & $\begin{array}{l}\text { Percent Chronic } \\
\text { Composite (PQI } \\
\text { 92) Admissions }\end{array}$ & $\begin{array}{l}\text { Percent Overall } \\
\text { Composite (PQI } \\
\text { 90) Admissions }\end{array}$ \\
\hline & $N=1,371,401$ & $N=142,260$ & $N=39,578$ & $N=181,836$ \\
\hline Male & 48.7 & 48.9 & 48.5 & 48.6 \\
\hline \multicolumn{5}{|l|}{ Age } \\
\hline $20-44$ & 20.2 & 19.9 & 20.4 & 20.3 \\
\hline $45-64$ & 34.2 & 33.9 & 34.1 & 34.0 \\
\hline ...65 plus & 45.7 & 46.2 & 45.6 & 45.7 \\
\hline \multicolumn{5}{|l|}{ Race and Ethnicity* } \\
\hline Other/Unknown & 7.9 & 7.9 & 7.9 & 7.9 \\
\hline Non-Hispanic White & 42.0 & 43.3 & 42.0 & 42.3 \\
\hline Non-Hispanic Black & 35.2 & 33.5 & 35.3 & 34.9 \\
\hline Hispanic & 12.4 & 12.6 & 12.2 & 12.3 \\
\hline Asian & 2.5 & 2.7 & 2.6 & 2.6 \\
\hline \multicolumn{5}{|l|}{ 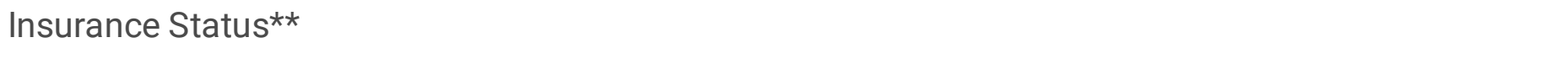 } \\
\hline Other/Unknown & 1.1 & 1.1 & 0.9 & 1.0 \\
\hline Private & 26.5 & 27.0 & 26.6 & 26.7 \\
\hline Medicaid & 19.6 & 19.2 & 19.7 & 19.6 \\
\hline Medicare & 48.6 & 48.5 & 48.6 & 48.6 \\
\hline Uninsured & 4.2 & 4.3 & 4.1 & 4.2 \\
\hline \multicolumn{5}{|c|}{ 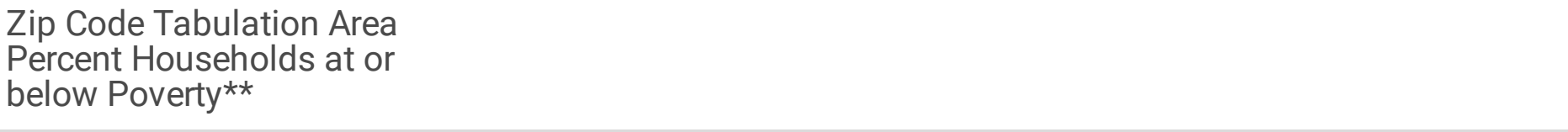 } \\
\hline$<5 \%$ & 18.8 & 19.4 & 19.0 & 19.0 \\
\hline $5-9.99$ & 25.0 & 25.3 & 24.8 & 24.9 \\
\hline $10-19.99$ & 28.8 & 29.6 & 28.9 & 29.1 \\
\hline 20 plus & 27.3 & 25.7 & 27.4 & 27.0 \\
\hline Weekend Admission & 21.6 & 21.7 & 21.6 & 21.7 \\
\hline
\end{tabular}

*P<.05 for comparison of Overall Composite PQI 90 and all admissions in sample ${ }^{* *} \mathrm{P}<.001$ for comparison of Overall Composite $\mathrm{PQI} 90$ and all admissions in sample 


\section{Table 2}

Average Annual Admission Rates per 1000 for Adult Cook County Residents by Zip Code Tabulation Area Percent of Households Living in Poverty, 2016-2018*, By Admission Type

$\mathrm{N}=1,371,401$ admissions to 174 Illinois Hospitals 


\begin{tabular}{|c|c|c|c|c|c|}
\hline $\begin{array}{l}\text { Composite } \\
\text { Ambulatory Care } \\
\text { Sensitive } \\
\text { Condition }\end{array}$ & $\begin{array}{l}<5 \% \text { of } \\
\text { ZCTA } \\
\text { Households } \\
\text { Poor }\end{array}$ & $\begin{array}{l}5-9.99 \% \text { of } \\
\text { ZCTA } \\
\text { Households } \\
\text { Poor }\end{array}$ & $\begin{array}{l}10-19.99 \% \text { of } \\
\text { ZCTA } \\
\text { Households } \\
\text { Poor }\end{array}$ & $\begin{array}{l}>20 \% \text { of } \\
\text { ZCTA } \\
\text { Households } \\
\text { Poor }\end{array}$ & $\begin{array}{l}\text { All Cook County } \\
\text { Residents Age } \\
20 \text { or Older }\end{array}$ \\
\hline $\begin{array}{l}\text { Census } \\
\text { Population } \\
\text { Estimates }\end{array}$ & 911,249 & $1,051,351$ & $1,175,109$ & 763,033 & $3,900,742$ \\
\hline
\end{tabular}

Overall Composite ACSC Admission Rates

\begin{tabular}{lccccc}
$\begin{array}{l}\text { Rate per 1000 } \\
\text { Total Adult } \\
\text { Population Age } \\
20+\end{array}$ & 12.67 & 14.35 & 15.00 & 21.44 & 15.54 \\
\hline $\begin{array}{l}\text { Rate per 1000 Age } \\
20-44\end{array}$ & 3.97 & 5.19 & 6.47 & 10.71 & 6.45 \\
$\begin{array}{l}\text { Rate per 1000 Age } \\
45-64\end{array}$ & 9.71 & 12.90 & 16.69 & 26.74 & 15.92 \\
$\begin{array}{l}\text { Rate per 1000 Age } \\
65+\end{array}$ & 36.61 & 39.82 & 40.29 & 42.56 & 39.59 \\
\hline
\end{tabular}

All Other Medical DRGs

$\begin{array}{llllll}\text { Rate per } 1000 & 57.82 & 69.46 & 75.44 & 117.13 & 77.87 \\ \text { Total Adult } & & & & & \\ \text { Population Age } & & & & & \\ 20+ & & & & \end{array}$

\begin{tabular}{|lccccc|}
\hline $\begin{array}{l}\text { Rate per 1000 Age } \\
20-44\end{array}$ & 20.56 & 27.91 & 33.38 & 59.21 & 34.35 \\
\hline $\begin{array}{l}\text { Rate per 1000 Age } \\
45-64\end{array}$ & 40.49 & 59.04 & 82.44 & 147.07 & 78.43 \\
$\begin{array}{l}\text { Rate per 1000 Age } \\
65+\end{array}$ & 168.20 & 191.94 & 203.03 & 228.51 & 195.28 \\
\hline
\end{tabular}

All Other Surgical DRGs

$\begin{array}{llllll}\text { Rate per } 1000 & 23.73 & 25.06 & 21.79 & 25.17 & 23.78 \\ \text { Total Adult } & & & & \\ \text { Population Age } & & & & \\ 20+ & & & & \end{array}$




\begin{tabular}{|c|c|c|c|c|c|}
\hline $\begin{array}{l}\text { Rate per } 1000 \text { Age } \\
20-44\end{array}$ & 5.17 & 6.97 & 7.48 & 10.98 & 7.55 \\
\hline $\begin{array}{l}\text { Rate per } 1000 \text { Age } \\
45-64\end{array}$ & 22.03 & 26.37 & 26.44 & 31.02 & 26.25 \\
\hline $\begin{array}{l}\text { Rate per } 1000 \text { Age } \\
65+\end{array}$ & 67.19 & 67.82 & 60.53 & 55.32 & 63.41 \\
\hline \multicolumn{6}{|c|}{ High Charlson Score (4+) } \\
\hline $\begin{array}{l}\text { Rate per } 1000 \\
\text { Population Age } \\
20+\end{array}$ & 22.11 & 27.53 & 29.17 & 44.03 & 29.99 \\
\hline $\begin{array}{l}\text { Rate per } 1000 \text { Age } \\
20-44\end{array}$ & 1.38 & 2.31 & 3.50 & 7.89 & 3.61 \\
\hline $\begin{array}{l}\text { Rate per } 1000 \text { Age } \\
45-64\end{array}$ & 11.30 & 21.28 & 30.46 & 51.56 & 27.82 \\
\hline $\begin{array}{l}\text { Rate per } 1000 \text { Age } \\
65+\end{array}$ & 82.62 & 101.74 & 113.16 & 135.03 & 105.80 \\
\hline
\end{tabular}

*Based on Zip Code Tabulation Area Population Estimates from the 2017 5-Year American Community Survey. All rate differences across areas were significant $p<.001$.

\section{Figures}




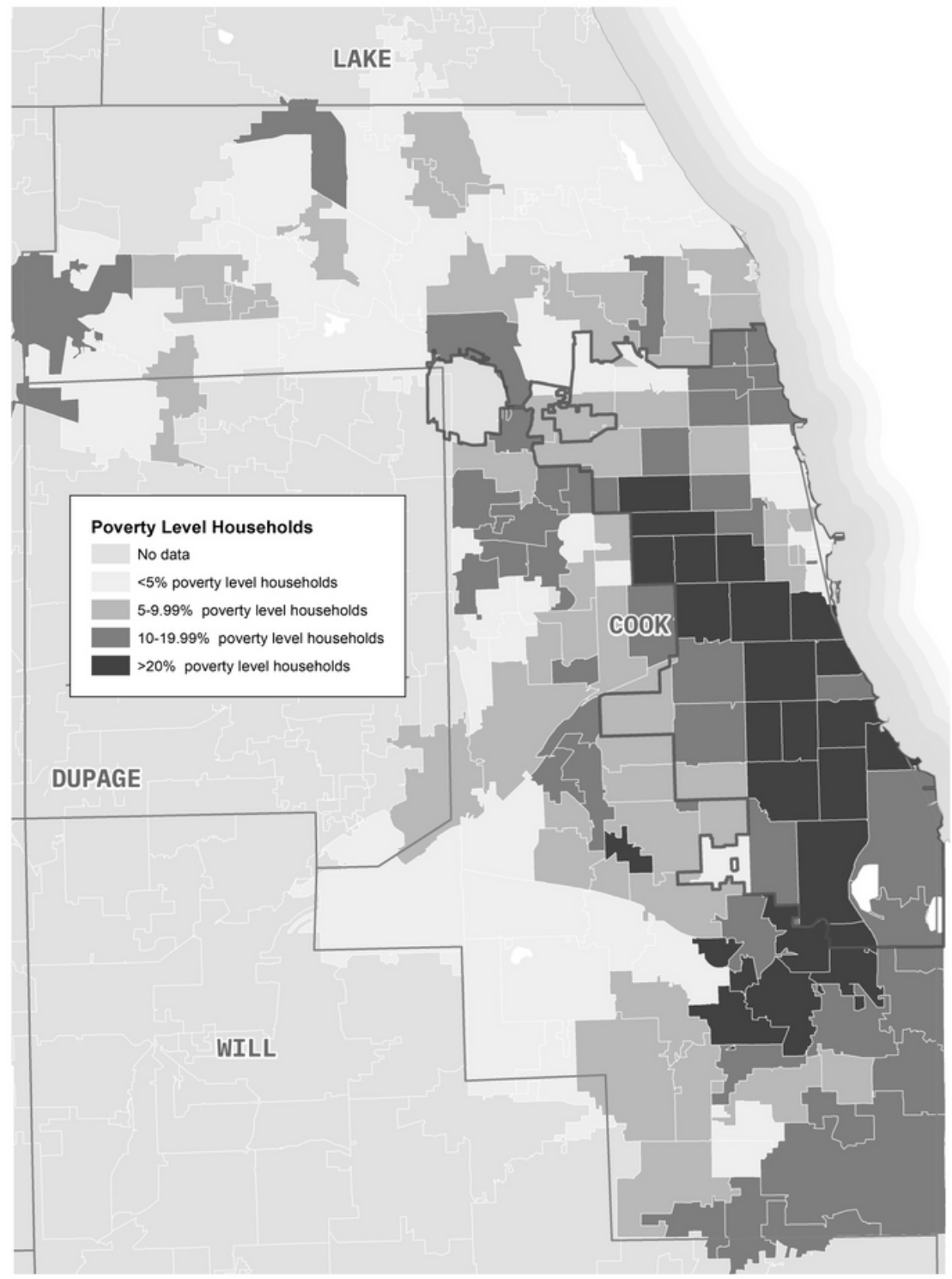

Figure 1

Zipcode Census Tract Area by Poverty Level, Cook County, Illinois, mapped using ESRI ArcGIS PRO software (Plantation, $\mathrm{FL}$ ). 


\section{Monthly Ambulatory Care Sensitive Hospital Admission in Cook County}

by Zip Code Tabulation Area Percent of Households at or Below Poverty

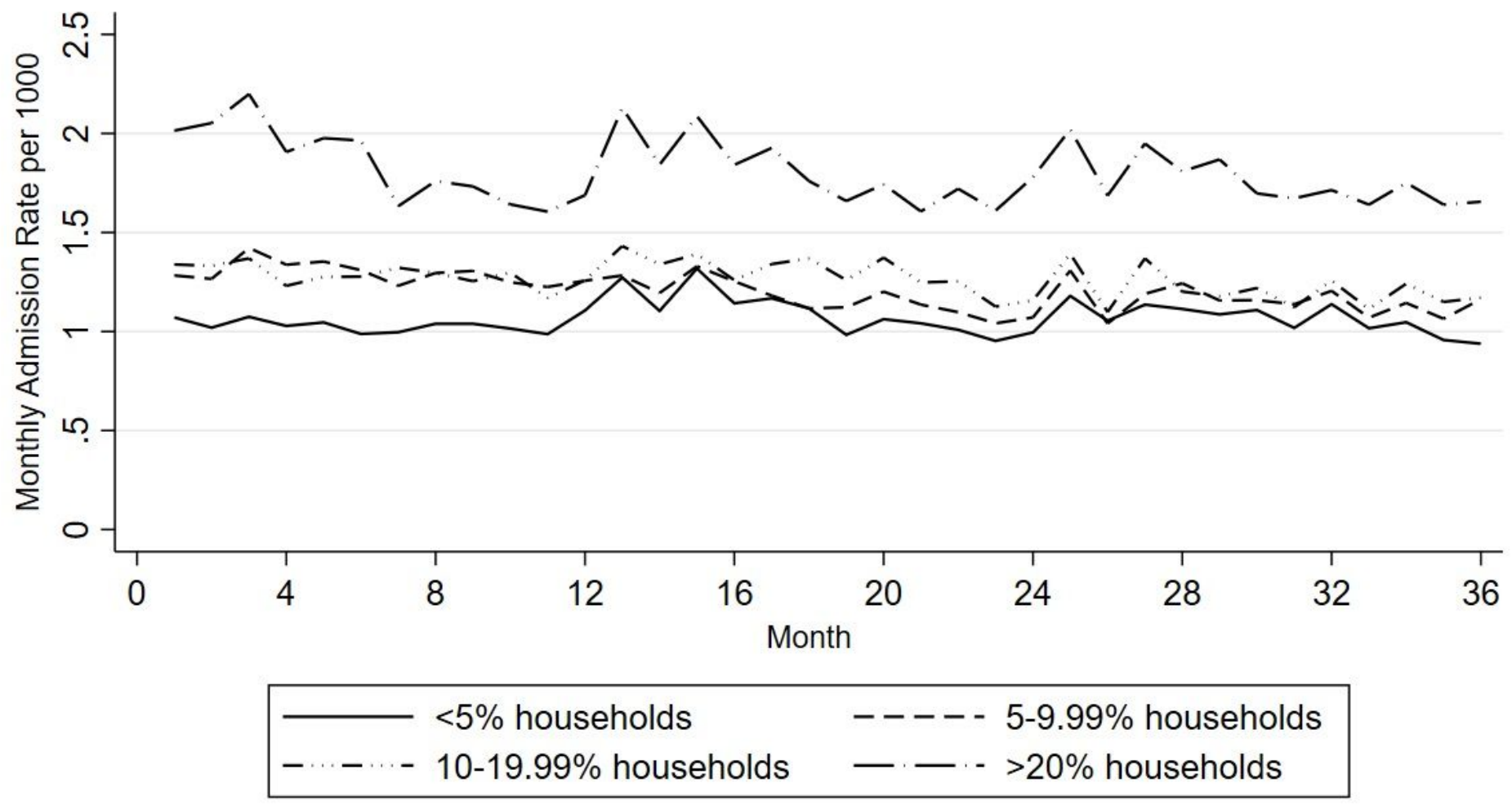

Figure 2

Monthly Ambulatory Care Sensitive Hospital Admission in Cook County by Zip Code Tabulation Area Percent of Households at or Below Poverty 


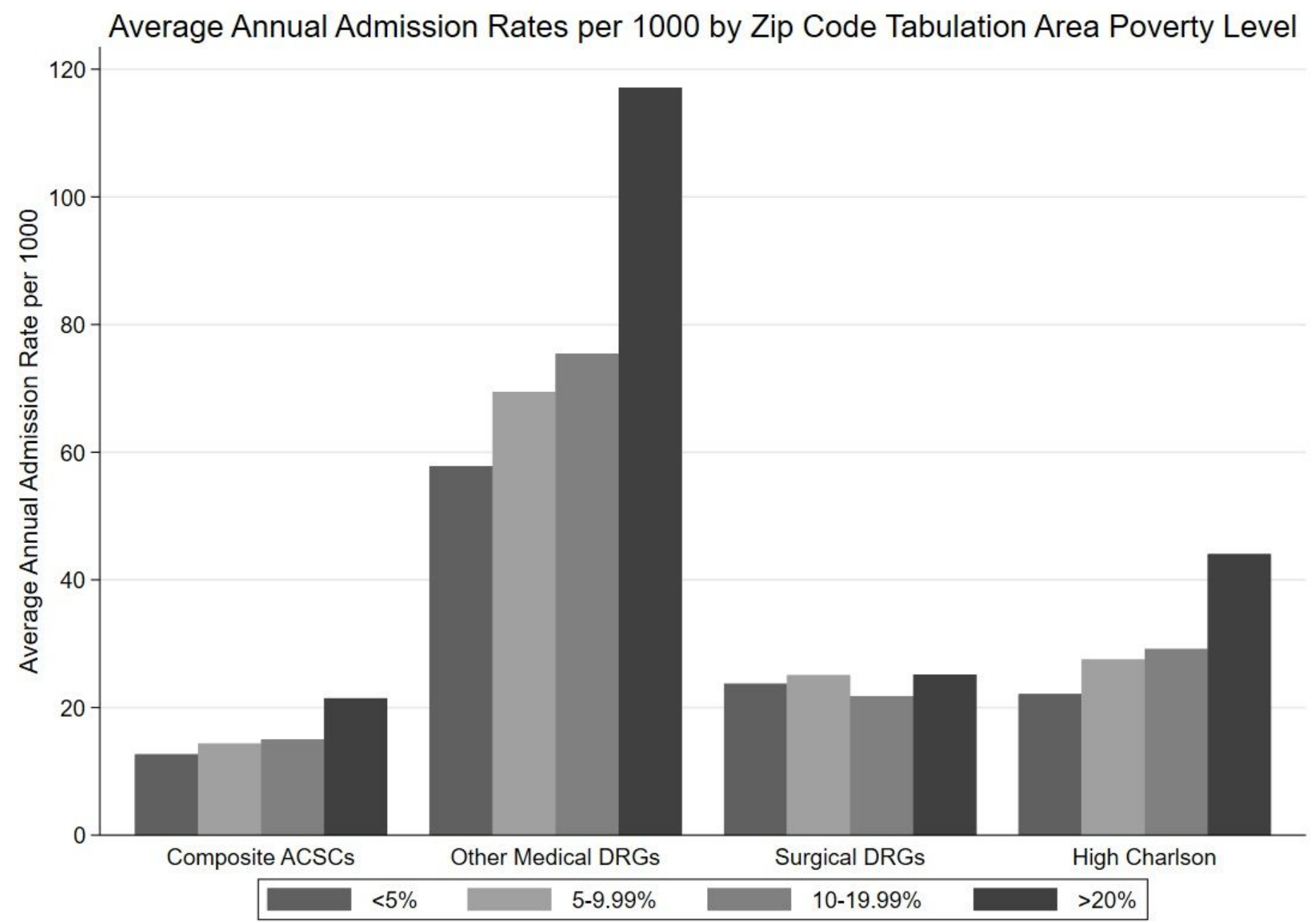

Figure 3

Average annual Admision rates per 1000 by zip code Tabulation area poverty level

\section{Supplementary Files}

This is a list of supplementary files associated with this preprint. Click to download.

- Appendixl1.docx 